\title{
Improving Combination Cancer Therapy by Acetaminophen and Romidepsin in Non-small Cell Lung Cancer Cells
}

\author{
Seong-Min Lee ${ }^{1, *}$, James S. Park ${ }^{2, * *}$ and Keun-Sik Kim ${ }^{1, \dagger, * *}$ \\ ${ }^{I}$ Department of Biomedical Laboratory Science, Konyang University, Daejeon 35365, Korea \\ ${ }^{2}$ Department of Medicine, NYU Langone Health, New York, NY 10016, USA
}

\begin{abstract}
Combination chemotherapy is more effective than mono-chemotherapy and is widely used in clinical practice for enhanced cancer treatment. In this study, we investigated the potential synergistic effects of acetaminophen, a common component in many cold medicines, and romidepsin, a histone deacetylase (HDAC) inhibitor, in the A549 non-small cell lung cancer (NSCLC) cell line. The combination of acetaminophen and romidepsin also exerted significant cytotoxicity and apoptosis induced by activation of caspase-3 on tumor cells in vitro. Moreover, combination therapy significantly induced increased production of chemokines that stimulate migration of activated T-cells into tumor cells. This mechanism can lead to active T-cell mediated anti-tumor immunity in addition to the direct cytotoxic chemotherapeutic effect. Activated T-cells led to enhanced cytotoxicity in drug-treated A549 cells through interaction with tumor cells. These results suggested that the interaction between the two drugs is synergistic and significant. In conclusion, our data showed that the use of romidepsin and low concentrations acetaminophen could induce effective anti-tumor effects via enhanced tumor immune and direct cytotoxic chemotherapeutic responses. The combination of acetaminophen with romidepsin should be considered as a promising strategy for the treatment of lung cancer.
\end{abstract}

Key Words: Chemotherapy, Acetaminophen, Romidepsin, Histone deacetylase inhibitor, A549 cells

\section{INTRODUCTION}

Lung cancer is one of the most common of cancer worldwide. There are multiple subtypes, but lung cancers can be categorized into the 2 following two major subtypes: smallcell lung cancer (SCLC) and non-small-cell lung cancer (NSCLC) (Rivas-Fuentes et al., 2015). According to studies, NSCLC accounts for approximately $80 \sim 85 \%$ of all lung cancer cases. Depending on the staging of lung cancer, patients are eligible for certain treatments ranging from sur- gery to radiation to chemotherapy, as well as targeted therapy (Provencio et al., 2011; Liu et al., 2018).

Recently, it was demonstrated that a cold medicine used to alleviate pain and reduce fever was effective in cancer therapy. Additionally, many other researchers exhibited that another cold medicine was effective in inhibiting bladder cancer (Matsumoto et al., 2016). Most medicines used to ease symptoms of cold consist of non-steroidal anti-inflammatory drugs (NSAIDs). NSAIDs are frequently used as analgesic and antipyretic drugs that most probably exert their antifever effect by inhibiting cyclooxygenase (COX)-2 (Jozwiak-

Received: September 23, 2019 / Revised: October 17, 2019 / Accepted: October 17, 2019

* Graduate student, ${ }^{* *}$ Professor.

† Corresponding author: Keun-Sik Kim. Department of Biomedical Laboratory Science, Konyang University, College of Medical Science, Daejeon 35365, Korea.

Tel: +82-42-600-8434, Fax: +82-42-600-8408, e-mail: kskim11@konyang.ac.kr

(C) The Korean Society for Biomedical Laboratory Sciences. All rights reserved.

(c) This is an Open Access article distributed under the terms of the Creative Commons Attribution Non-Commercial License (http://creativecommons.org/licenses/by-nc/3.0/) which permits unrestricted non-commercial use, distribution, and reproduction in any medium, provided the original work is properly cited. 
Bebenista and Nowak, 2014). Several studies have demonstrated that acetaminophen in particular, induces apoptosis and necrosis in a variety of cells, including cancer cells. Acetaminophen is an antipyretic and analgesic agent, similar to NSAIDs, and has been shown to exert significant anticancer effects in tumor cells. However, long-term acetaminophen administration can lead to serious hepatotoxicity as a main side effect (Liang et al., 2012; Posadas et al., 2012; Yu et al., 2014). Therefore, determining the appropriate acetaminophen treatment concentration should be the main consideration in therapeutic decisions.

Romidepsin is one of a depsipeptide small molecule (MW=540.7) belonging to histone deacetylase (HDAC) inhibitors (Valdez et al., 2015). Several HDAC inhibitors have been reported to act as tumor suppressors that either indirectly contribute to tumor cell death by inducing changes in cell cycle distribution or directly induce apoptosis in various cancer cells (Vinodhkumar et al., 2008; Gao et al., 2014). Interestingly, HDAC inhibitors are known to induce expression of multiple $\mathrm{T}$ cell chemokines such as $\mathrm{C}-\mathrm{C}$ motif chemokine ligand 5 (CCL5) and C-X-C motif chemokine ligand 10 (CXCL10), thus recruiting effectors T-cells to tumor cells. Therefore, expression of these $\mathrm{T}$ cell chemokines can lead to effective active immunity (Zheng et al., 2016). Despite these advantages, most of the known HDAC inhibitors when used as a single agent in treatment protocols failed to show any clinical benefits in nearly all types of solid tumors tested, including renal and breast cancer (Slingerland et al., 2014). Therefore, many researchers have explored the combination of HDAC inhibitors with other anticancer drugs as a potential treatment scheme that might result in an optimal effect (Suraweera et al., 2018). In this study, we investigated the antitumor effect of the combined acetaminophen and romidepsin drugs in the A549 human non-small-cell lung carcinoma (NSCLC) cell line. In particular, we confirmed that combination therapy increased the expression of $\mathrm{T}$ cell chemokines, which in turn led to the effective migration of Jurkat cells, a human T-cell lymphoma. These results are promising precursors that might eventually lead to better immunotherapy based on the added interaction between $\mathrm{T}$ cells and tumor cells.

\section{MATERIALS AND METHODS}

\section{Reagents}

Cold medicine, Pancold-S Oral Solution, was purchased from Dongwha Pharm Co Ltd (Seoul, Korea). Acetaminophen and romidepsin were purchased from Sigma-Aldrich (St. Louis, MO, USA) Acetaminophen was dissolved in $0.5 \mathrm{M}$ ethyl alcohol and romidpsin was dissolved in dimethyl sulfoxide (DMSO). PMA (phorbol 12-myristate 13-acetate) and Ionomycin were purchased from Sigma-Aldrich.

\section{Cell culture}

Human non-small-cell lung cancer (NSCLC) A549 cells and Jurkat T cells (clone E6-1) were purchased from American Type Culture Collection (ATCC, Manassas, VA, USA). The cells were maintained in RPMI1640medium (Hyclone, Logan, UT, USA) supplemented with $10 \%$ heatinactivated fetal bovine serum (FBS) (Gibco/Invitrogen, Carlsbad, CA, USA), $1 \%$ penicillin/streptomycin (Hyclone, Logan, UT, USA) in a humidified atmosphere with $5 \% \mathrm{CO}_{2}$ at $37^{\circ} \mathrm{C}$.

\section{Cell viability assay}

A549 cells $\left(2 \times 10^{4}\right.$ cells/well $)$ were seeded in 96-well plates and incubated $24 \mathrm{~h}$. The cells were then treated with various concentration of cold medicine, acetaminophen and romidepsin for 24 and $48 \mathrm{~h}$. After incubation for 24 and $48 \mathrm{~h}$, the medium was exchanged with a fresh medium containing EZ-Cytox reagent $10 \mu \mathrm{L}$ (Daeil lab service, Seoul, South Korea) and incubated for $2 \mathrm{~h}$ at $37^{\circ} \mathrm{C}$. The absorbance was measured at $450 \mathrm{~nm}$ by using a VersaMax microplate reader (Molecular Device, Sunnyvale, CA, USA).

\section{Cell cycle analysis}

A549 cells $\left(9 \times 10^{4}\right.$ cells/well $)$ were seeded in 24 -well plates and incubated $24 \mathrm{~h}$. A549 cells were treated with the indicated dose of cold medicine for $48 \mathrm{~h}$ were harvested and washed with PBS, and then fixed with $70 \%$ ice-cold ethanol at $-20^{\circ} \mathrm{C}$ overnight. After incubation overnight, the cells were washed and then stained by adding $200 \mu \mathrm{L}$ of propidium iodide for $30 \mathrm{~min}$ at room temperature in the 
dark. The DNA content was analyzed by NovoCyte Flow Cytometer (ACEA Bioscience, San Diego, CA, USA). All tests were performed in triplet.

\section{Apoptosis assay}

To determine the effect of combined treatment with acetaminophen and romidepsin, A549 cells $\left(9 \times 10^{4}\right.$ cells/well in 24-well plates) were determined using annexin $\mathrm{V}$ apoptosis kit. The cells were treated with the indicated concentration of acetaminophen $(3 \mathrm{mM})$ or/and romidepsin $(7 \mathrm{nM})$ for 48 h. Control cells were combined treatment with EtOH and DMSO. After $48 \mathrm{~h}$, the cells were washed twice with PBS and the cells were counted and $1 \times 10^{5}$ cells were resuspended in $100 \mu \mathrm{L}$ of binding buffer. And then, addition of $5 \mu \mathrm{L}$ annexin V-FITC and $5 \mu \mathrm{L}$ PI (BD Biosciences, San Jose, CA, USA) and incubation for $15 \mathrm{~min}$ at room temperature in the dark. Subsequently, $400 \mu \mathrm{L}$ of binding buffer were added and the early and late apoptotic cells were analyzed by flowcytometry. All tests were performed in triplet.

\section{Western blotting}

A549 cells $\left(2 \times 10^{5}\right.$ cells/well in 6-well plates) treated with acetaminophen and/or romidepsin for $48 \mathrm{~h}$ were harvested and washed with cold PBS. Cell pellets were lysed using a RIPA lysis buffer for $10 \mathrm{~min}$ on ice. Lysates were centrifuged at $10,000 \times \mathrm{g}$ for $10 \mathrm{~min}$ at $4{ }^{\circ} \mathrm{C}$, and protein supernatant was measured by BCA protein assay reagent (Thermo Fisher Scientific, Waltham, MA, USA). The protein lysates $(15 \mu \mathrm{g})$ were separated by either $10 \%$ or $12 \%$ sodium dodecyl sulfate polyacrylamide gel electrophoresis (SDS-PAGE). The proteins were transferred onto PVDF membrane (GE Healthcare, Freiburg, Germany) and were blocked with 5\% skimmed milk for $1 \mathrm{~h}$. Then, incubated overnight with appropriate primary antibodies against anti$\beta$-actin antibody $(1: 1,000)$ (Santa Cruz Biotechnology, Santa Cruz, CA, USA) and caspase-3 antibody $(1: 1,000)$ (Cell signaling Technology, Beverly, MA, USA). After incubation with primary antibody, the membranes were incubated for $1 \mathrm{~h}$ at room temperature with horse radish peroxidase (HRP) conjugated secondary antibody $(1: 2,000$, anti-mouse antibody or anti-rabbit antibody) (Cell signaling Technology, Beverly, MA, USA). The protein signals were developed using an enhanced chemiluminescence detection system (ECL) (Thermo Fisher Scientific, Waltham, MA, USA).

\section{Enzyme-linked immunosorbent assay}

A549 cells $\left(2 \times 10^{5}\right.$ cells/well in 6-well plates $)$ were treated with acetaminophen and/or romidepsin for $48 \mathrm{~h}$. The cell culture supernatants were harvested and the secretion levels of CCL5 and CXCL10 in cell culture were assayed using a human CCL5/RANTES and CXCL10/IP-10 DuoSet ELISA kit (R\&D systems, Minneapolis, MN, USA) following the manufacturer's protocols. The absorbance was measured at $450 \mathrm{~nm}$ by using a microplate reader. All assays were performed as three independent experiments.

\section{Co-culture experiments}

A549 cells were pretreated with acetaminophen $(3 \mathrm{mM})$ and romidepsin $(7 \mathrm{nM})$ for $24 \mathrm{~h}$ and washed twice with PBS. Jurkat cells were activated with PMA and Ionomycin and then co-cultured with A549 cells at effector to target (E-T) ratio of 5:1 for $48 \mathrm{~h}$. Plates were wash with PBS twice and the living cells were stained with crystal violet solution for $5 \mathrm{~min}$. After drying, the colonies were observed and intensity was quantified.

\section{Statistical analysis}

Data are presented as means \pm standard error (SD). Statistical significance of differences was examined by $t$-test or one-way ANOVA. The results with $P<0.05$ was considered as statistically significant.

\section{RESULTS}

\section{Inhibition of proliferation and induction of cell cycle arrest by cold medicine in A549 cells}

The inhibitory effect of cold medicine on cell growth and proliferation was determined using the WST cell viability and proliferation assay in A549 cells. Cells were treated with the indicated concentration of cold medicine for 24 or 48 h. Proliferation of A549 cells was inhibited in a doseand time-dependent manner (Fig. 1A). To determine whether the anti-proliferative effect was due to cell cycle arrest, cells were treated with $10 \%(\mathrm{v} / \mathrm{v})$ cold medicine at half maximal 
(A)

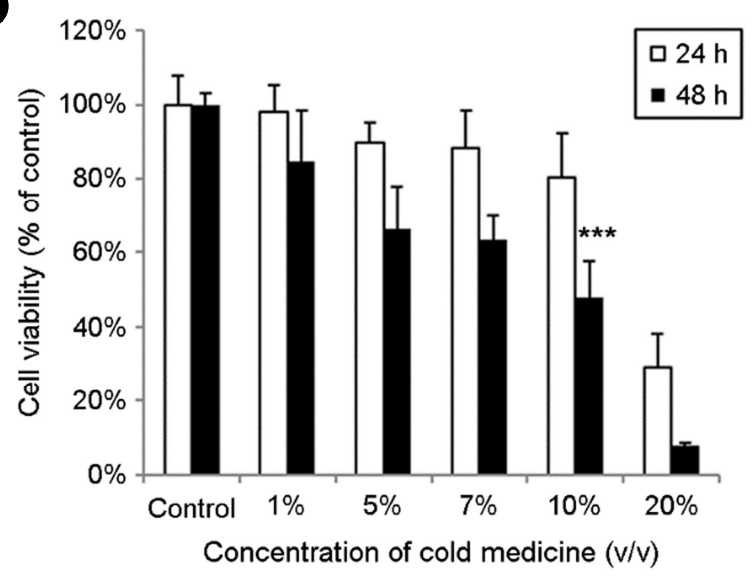

B

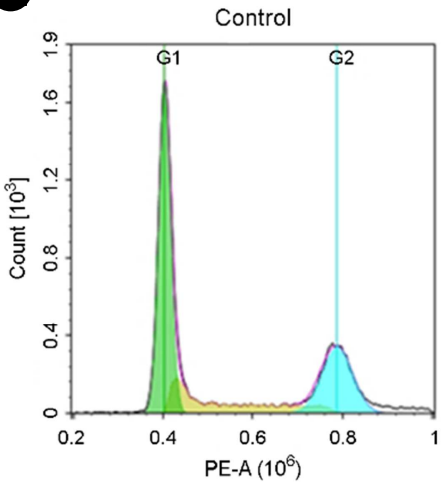

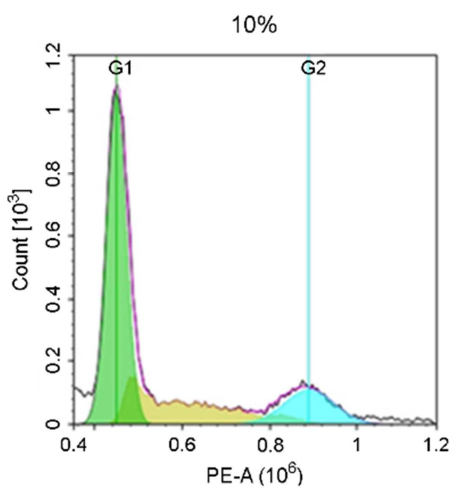

C

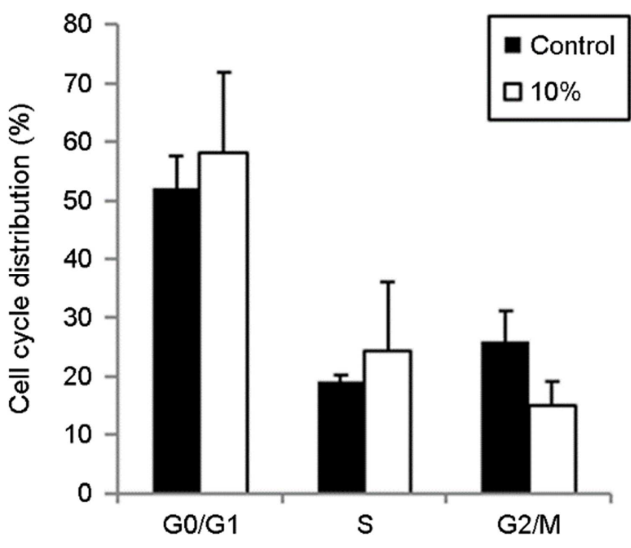

Fig. 1. Inhibition of proliferation and induction of G1-phase cell-cycle arrest by cold medicine. (A) A549 cells were treated with various concentration of cold medicine $(1 \sim 20 \%, \mathrm{v} / \mathrm{v})$ for $24 \mathrm{~h}$ or $48 \mathrm{~h}$. Cell viability was evaluated by WST assay. (B) A549 cells were treated with $10 \%\left(\mathrm{IC}_{50}\right)$ of cold medicine for $48 \mathrm{~h}$, then cells were harvested and stained with PI. Cell cycle distribution was analyzed by flow cytometry. (C) Histogram of cell cycle arrest percentage obtained after FACS analysis. Data are presented as mean \pm SD for triplicate experiments. $* * * P<0.001$ compared with the control group.

inhibitory concentration $\left(\mathrm{IC}_{50}\right)$ value for $48 \mathrm{~h}$. Cell cycle distribution and nuclear DNA content were determined by flow cytometric analysis. As shown in Fig. $1 \mathrm{~B}$ and $1 \mathrm{C}$, the cold medicine treatment group showed the increasing popuation of cells in G0/G1 phase of cell cycle compared to control group. These findings indicated that cold medicine induces cell cycle arrest and inhibits cell proliferation of A549 cells.

\section{Inhibition of A549 cell viability by acetaminophen- romidepsin administration}

We evaluated the cytotoxicity of acetaminophen or romidepsin, or both, using the WST cell viability and proliferation assay in A549 cells. When treated with acetaminophen alone (1 10 mM), proliferation of A549 cells was inhibited in a dose-and time-dependent manner. The mean $\mathrm{IC}_{50}$ value of acetaminophen was $7 \mathrm{mM}$ for a $48 \mathrm{~h}$ incubation (Fig. 2A). In addition, romidepsin showed anti-proliferation effects in
A549 cells. The $\mathrm{IC}_{50}$ value of romidepsin was $10 \mathrm{nM}$ following a $48 \mathrm{~h}$ incubation (Fig. 2B). In order to study the synergistic effect of acetaminophen and romidepsin, A549 cells were treated with acetaminophen $\left(\mathrm{IC}_{25}: 3 \mathrm{mM}\right)$ and romidepsin $\left(\mathrm{IC}_{25}: 7 \mathrm{nM}\right)$ for 24 or $48 \mathrm{~h}$. As shown in Fig. 2C, the combination of acetaminophen $(3 \mathrm{mM})$ and romidepsin $(7 \mathrm{nM})$ significantly decreased cell viability (28\%) compared with when cells were treated for $48 \mathrm{~h}$ with acetaminophen $(75 \%)$ or romidepsin $(75 \%)$ alone. These results revealed that the combination of acetaminophen and romidepsin is a more effective anti-cancer agent in A549 cells.

\section{Synergistic induction of apoptosis in A549 cells by com- bined treatment of acetaminophen and romidepsin}

We examined the apoptosis induced by administration of acetaminophen $(3 \mathrm{mM})$ or romidepsin $(7 \mathrm{nM})$, or both, using flow cytometry. The combination treatment induced an increase of apoptotic cells compared with when acetaminophen 
A

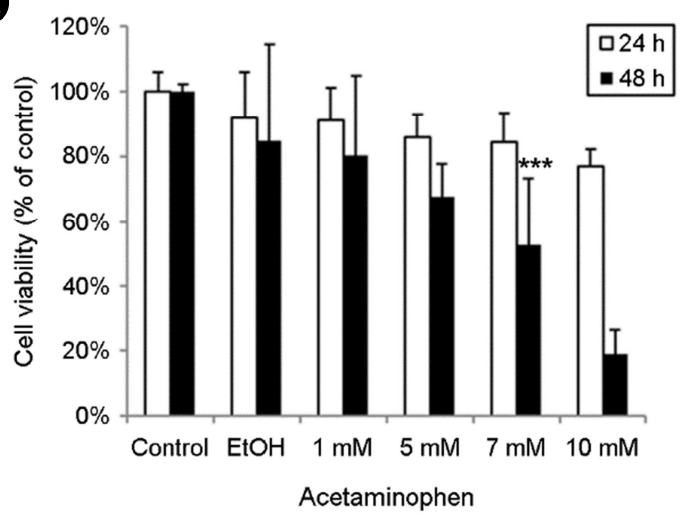

C

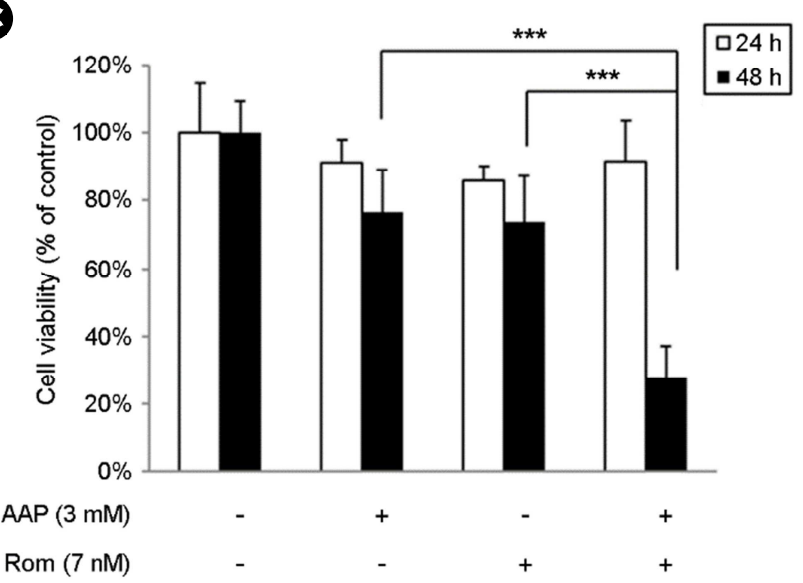

B

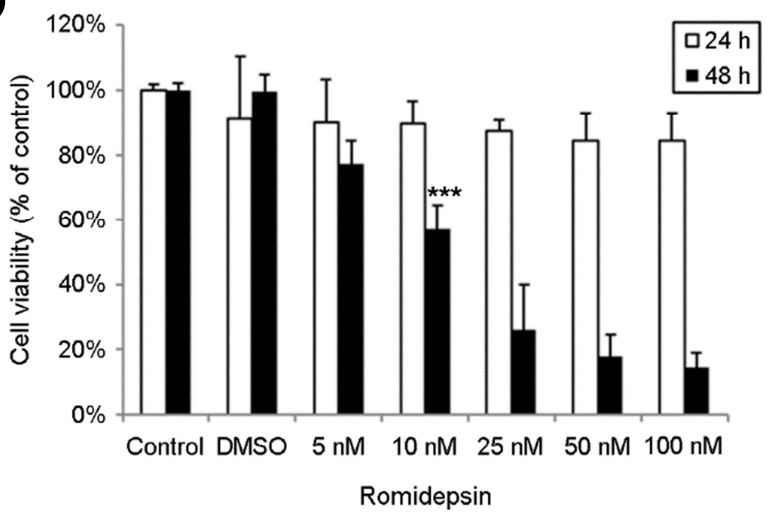

Fig. 2. Inhibition of A549 cells viability by combination of acetaminophen and romidepsin. A549 cells were treated with various concentration $(1 \sim 10 \mathrm{mM})$ of acetaminophen (A) or various concentration $(5 \sim 100 \mathrm{nM})$ of romidepsin (B) for 24 or $48 \mathrm{~h}$. These A549 cells were treated with for 24 or $48 \mathrm{~h}$, then cell survival was measured by WST assay. (C) A549 cells were treated with acetaminophen $(3 \mathrm{mM})$ or/and Romidepsin $(7 \mathrm{nM})$ for 24 or $48 \mathrm{~h}$. Error bars represent SD of three independent experiments. A; $* * * P<0.001$ compared with the control. B; $* * * P<0.001$ compared with the control. C; *** $P<0.001 \mathrm{com}-$ pared with acetaminophen or romidepsin respectively. or romidepsin was administered alone. As shown in Fig. 3A and $3 \mathrm{~B}$, the percentage of apoptotic cells in A549 cultures treated with acetaminophen $(3 \mathrm{mM})$ and romidepsin $(7 \mathrm{nM})$ for $48 \mathrm{~h}$, was $29 \%$ and $10 \%$, respectively. However, the percentage of apoptotic cells following combination treatment for $48 \mathrm{~h}$ was $63 \%$. To determine whether cell death by apoptosis was associated with caspase 3 activity, western blot analysis of caspase 3 was performed to confirm caspase activity. The combination treatment remarkable induced caspase 3 activation compared with treatment with acetaminophen (3 mM) or romidepsin (7 $\mathrm{nM})$ alone (Fig. 3C). These results suggested that combination treatment with acetaminophen and romidepsin effectively induced apoptosis through activation of caspase 3 .

\section{Induction of chemokines in A549 cells by combination treatment with acetaminophen and romidepsin}

Romidepsin has the characteristic property of inducing the production of chemokines, which induce in turn homing of T-cells. To determine whether acetaminophen would be able to induce a significant increase of CCL5 and CXCL10 production through combination with romidepsin, we evaluated the levels of CCL5 or CXCL10 secreted in the supernatants of A549 cells treated with these drugs ( $\mathrm{IC}_{25}$ values) by ELISA. Treatment with acetaminophen $(3 \mathrm{mM})$ or romidepsin $(7 \mathrm{nM})$ alone induced little change in the expression of chemokines (CCL5 and CXCL10) but the combination of the 2 drugs resulted highly 2 or 3 folds compared to the group by treatment alone in the production of chemokines (Fig. 4A and 4B). These results suggested that combination treatment induced the synergistic effect of these drugs on regulating the expression of chemokines.

\section{Cell growth inhibition of A549 cells co-cultured with Jurkat T-cells}

We previously identified an increased expression of che- 
A

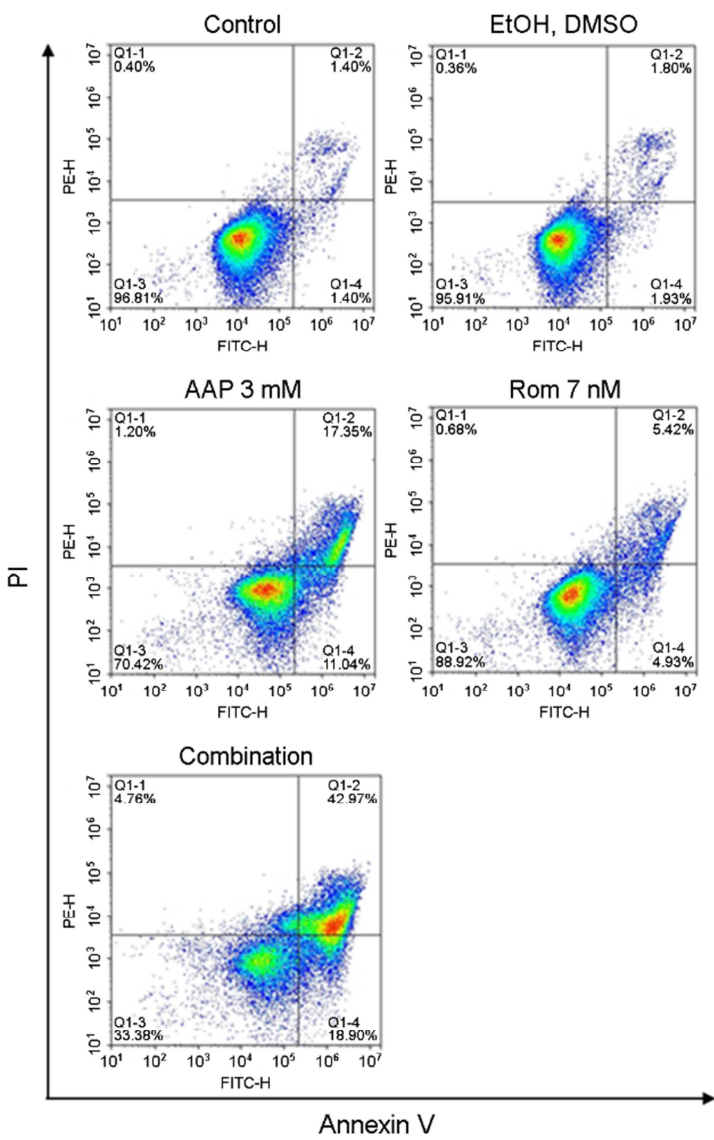

B

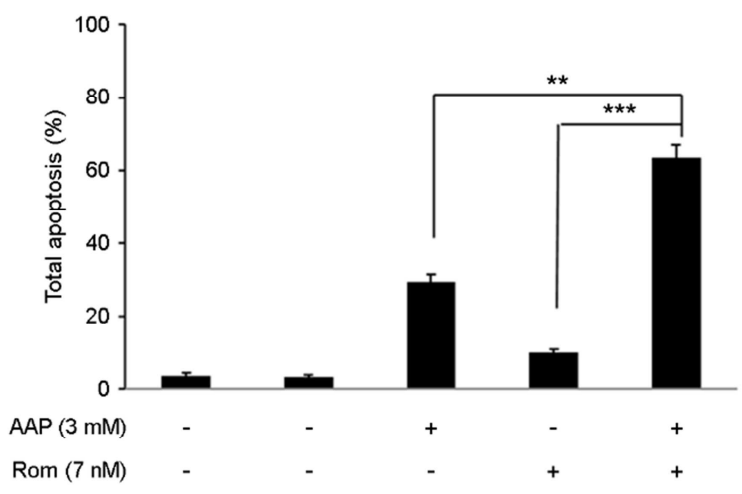

C

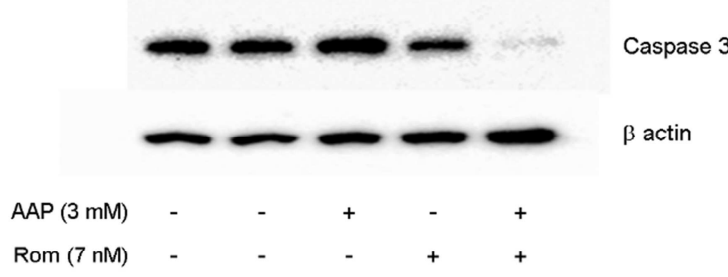

Fig. 3. Enhancement of apoptosis-induction in A549 cells by combination treatment with acetaminophen and romidepsin. (A) A549 cells were treated with acetaminophen $(3 \mathrm{mM})$ or/and romidepsin $(7 \mathrm{nM})$ for $48 \mathrm{~h}$, then early and late apoptosis was analyzed by flow cytometry. (B) Bar charts showed quantitative data for total apoptosis rate at each the treated group. (C) A549 cells were treated with acetaminophen $(3 \mathrm{mM})$ or/and romidepsin $(7 \mathrm{nM})$ for $48 \mathrm{~h}$, then the caspase-3 was determined by western blot analysis. The data are presented as means \pm SD for triplicate experiments. $\mathrm{B} ; * * P<0.01$ compared with acetaminophen, $* * * P<0.001$ compared with romidepsin.

A

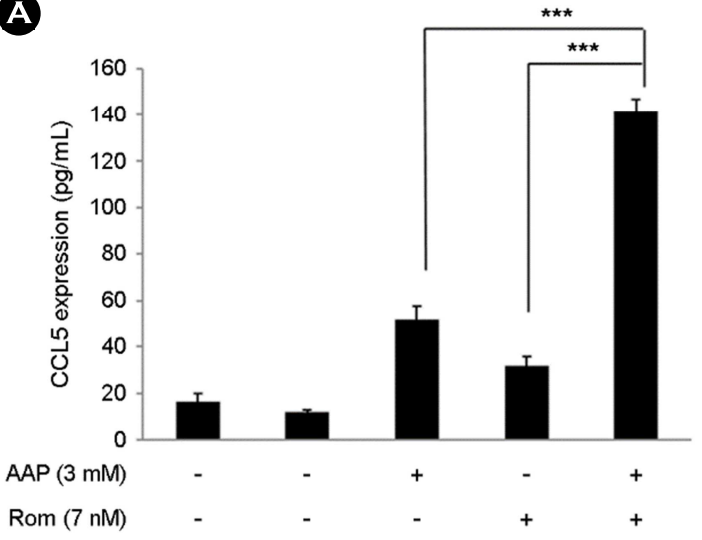

B

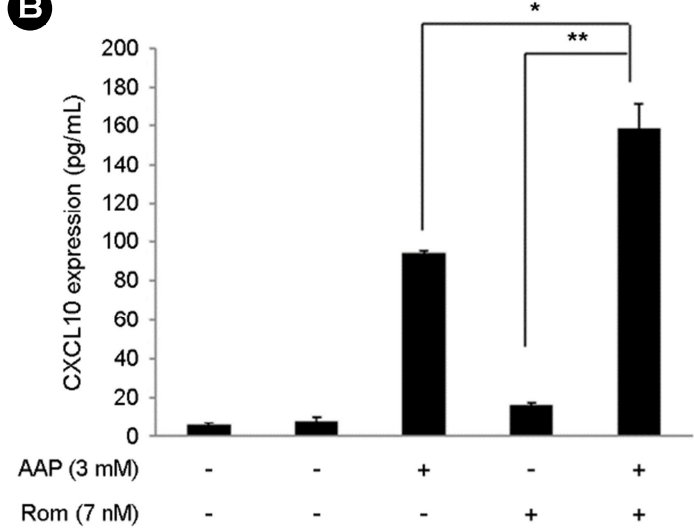

Fig. 4. Induction of T-cell chemokines in A549 cells by combined-treatment of acetaminophen and romidepsin. (A) A549 cells were treated with acetaminophen $(3 \mathrm{mM})$ or/and romidepsin $(7 \mathrm{nM})$ for $48 \mathrm{~h}$, and then the levels of CCL5 secretion was determined by ELISA. (B) The secreted levels of CXCL10 was determined by ELISA following the treatment with acetaminophen $(3 \mathrm{mM})$ or/and romidepsin $(7 \mathrm{nM})$ for $48 \mathrm{~h}$. Three independent experiments were performed and results shown as means \pm SD. A; $* * * P<0.001$ compared with acet aminophen, ${ }^{* * *} P<0.001$ compared with romidepsin. $\mathrm{B}$; $* P<0.01$ compared with acetaminophen, $* * P<0.01$ compared with romidepsin. 
(A)

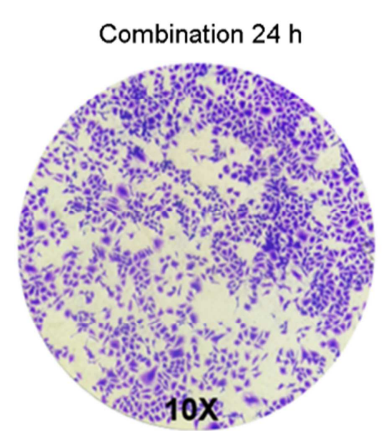

Combination $24 \mathrm{~h}+$

activated T cell co-culture $48 \mathrm{~h}$

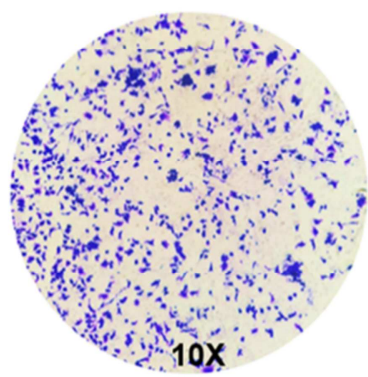

B

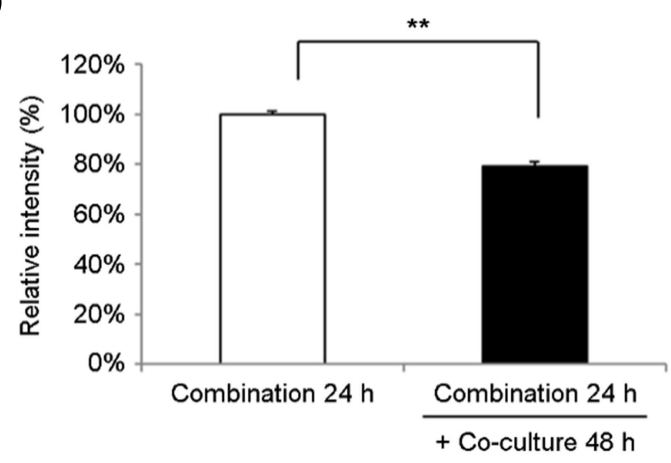

Fig. 5. Inhibition of A549 cells treated with combined-drug by Jurkat T cells. (A) A549 cells were treated with acetaminophen (3 mM) and romidepsin $(7 \mathrm{nM})$ for $24 \mathrm{~h}$, before co-cultured with activated Jurkat T cells with effector to target cell ratio of 5:1. After $48 \mathrm{~h}$ of coculture, live tumor cells were stained by crystal violet and measured by microscope (10X). (B) Bar charts showed quantitative data for surviving tumor cells stained by crystal violet. DATA are represented as means $\pm \mathrm{SD}$. B; $* * P<0.01$ compared with A549 alone treated with combination.

mokines in A549 cells due to the combined administration of the tested drugs. To determine whether these induced chemokines exhibit a similar cytotoxicity effect on A549 cells as the one shown by activated Jurkat cells, A549 cells were treated with acetaminophen and romidepsin for $24 \mathrm{~h}$ and then co-cultured with activated Jurkat cells for $48 \mathrm{~h}$. As shown Fig. 5, co-culturing of activated Jurkat cells with drug-treated A549 cells at effector (E) to target (T) cell ratio of 5:1 (E:T ratios) showed $21 \%$ reduction of cell viability compared with drug-treated A549 cells alone.

\section{DISCUSSION}

Cancer therapy has developed from general chemotherapy to combination chemotherapy. Although general chemotherapy is the main therapeutic approach used to treat cancers, there are limitations in treatment due to chemoresistance as well as due to the fact that it has been shown to be less effective than combination chemotherapy. In many types of research, combination therapies have focused on synergistic effect exerted in cancer therapy because each individual agent tested targets a different mechanisms (Bayat Mokhtari et al., 2017; Li et al., 2018; Saputra et al., 2018). Therefore, we tried to identify the potential cancer therapeutic effects exhibited between the 2 drugs tested here through a combination approach. We also confirmed the synergistic effect displayed by the released-cytokines (CCL5 and CXCL
-10) induced by the administered combination of these 2 drugs.

Recently, the studies examining the anticancer effect of drug components used to alleviate cold symptoms have been steadily increasing, and thus the range of agents applied to cancer therapy is getting wider. Acetaminophen, one of the components of cold medicine, is known to exhibit anticancer effects on a variety of cancer cells, but caution is needed in the case that high doses might be required because of its potential side effects that might even lead to hepatoma (Sayour et al., 2016).

Thus, we expected that combination of a low concentration of acetaminophen and other anticancer agents could be synergistic in cancer therapy and effective in minimizing these side effects. Especially, romidepsin, histone deacetylase (HDAC) inhibitor, is known to be more effective in combination therapy than mono-therapy (Suraweera et al., 2018). As such, many recent studies have focused primarily on examining the effects of the combination of romidepsin with other anticancer drugs (Petrich and Nabhan, 2016).

In our study, in order to select the appropriate concentrations for the combined administration of acetaminophen and romidepsin, the $\mathrm{IC}_{50}$ of both acetaminophen and romidepsin were determined (Fig. 2). Consecutively, synergistic administration of the $\mathrm{IC}_{25}$ value of each drug induced lower cell viability in $\mathrm{A} 549$ cells than when treated with the $\mathrm{IC}_{50}$ value of each drug alone. Although combination of the $\mathrm{IC}_{50}$ 
values of each drug induced less than $20 \%$ cell death, combination of the $\mathrm{IC}_{25}$ values was considered sufficient.

Apoptosis, as a process of programmed cell death, induces DNA damage in the cancer site and inhibits tumor growth. This can be initiated by 2 different mechanisms, an intrinsic pathway and an extrinsic pathway, which induces activation of caspase 3 and 7 (Pistritto et al., 2016; Bundscherer et al., 2018). This stimulated caspase activity results in the induced final apoptotic cell death (Stennicke and Salvesen, 2000). This stimulated caspase activity results in the induced final apoptotic cell death. We found that combination treatment with acetaminophen and romidepsin induced increased levels of apoptosis in A549 cells leading to the activation of caspase 3 (Fig. 3). Therefore, these results showed that combination of acetaminophen and romidepsin synergistically induces apoptosis by caspase 3 in A549 cells (Qin et al., 2002).

In addition, HDAC inhibitors are known to stimulate the expression of chemokines that induce leukocyte homing into tumors. Chemokines, such as CCL5 and CXCL10, induce lymphocyte migration through binding to specific receptors in a concentration-dependent manner (Stein and Nombela-Arrieta, 2005; Liu et al., 2015). T-cell infiltrating into tumor microenvironment can improve patient survival (Ward and Westwick, 1998; Hopewell et al., 2013). Based on these, we assumed that combination of acetaminophen with romidepsin would lead to the increased expression of more effective chemokines in A549 cells than when treated with a single drug (Fig. 4). Moreover, we predicted that increased production of chemokines would induce activated T-cells into the tumor microenvironment. when drug-treated A549 cells where co-cultured with activated T-cells, this resulted in increased induced T-cell mediated tumor killing compared to the drug-treated mono-cultured A549 cells (Fig. 5).

In conclusion, our results implied that combination treatment with acetaminophen and romidepsin synergistically induced cell death and apoptosis in A549 cells, through an increase in chemokine production and activation of caspase 3 . We conducted the co-culture system to identify the interaction of tumor cells with T-cells in the tumor microenvironment. Although the synergistic mechanism between these 2 drugs remains unclear, our results demonstrated that combination chemotherapy is more effective than single drug administration in human non-small-cell lung cancer (NSCLC) A549 cells.

\section{ACKNOWLEDGEMENT}

This research was supported by Basic Science Research Program through the National Research Foundation of Korea (NRF) funded by the Ministry of Education (NRF2018R1D1A1B07045861).

\section{CONFLICT OF INTEREST}

The authors have no conflict of interest to declare.

\section{REFERENCES}

Bayat Mokhtari R, Homayouni TS, Baluch N, Morgatskaya E, Kumar S, Das B, Yeger H. Combination therapy in combating cancer. Oncotarget. 2017. 8: 38022-38043.

Bundscherer AC, Malsy M, Gruber MA, Graf BM, Sinner B. Acetaminophen and metamizole induce apoptosis in ht 29 and sw 480 colon carcinoma cell lines in vitro. Anticancer Res. 2018. 38: 745-751.

Gao M, Gao L, Tao Y, Hou J, Yang G, Wu X, Xu H, Tompkins VS, Han Y, Wu H, Zhan F, Shi J. Proteasome inhibitor carfilzomib interacts synergistically with histone deacetylase inhibitor vorinostat in jurkat t-leukemia cells. Acta Biochim Biophys Sin. 2014. 46: 484-491.

Hopewell EL, Zhao W, Fulp WJ, Bronk CC, Lopez AS, Massengill M, Antonia S, Celis E, Haura EB, Enkemann SA, Chen D-T, Beg AA. Lung tumor $n f-\kappa b$ signaling promotes $t$ cell-mediated immune surveillance. The Journal of Clinical Investigation. 2013. 123: 2509-2522

Jozwiak-Bebenista M, Nowak JZ. Paracetamol: Mechanism of action, applications and safety concern. Acta Pol Pharm. 2014. 71: 11-23.

Li Y, Hu T, Chen T, Yang T, Ren H, Chen M. Combination treatment of fty 720 and cisplatin exhibits enhanced antitumour effects on cisplatin-resistant non-small lung cancer cells. Oncol Rep. 2018. 39: 565-572.

Liang YL, Zhang ZH, Liu XJ, Liu XQ, Tao L, Zhang YF, Wang $\mathrm{H}$, Zhang C, Chen X, Xu DX. Melatonin protects against apoptosis-inducing factor (aif)-dependent cell death during acetaminophen-induced acute liver failure. PLoS One. 2012. 7: 18 . 
Liu J, Cheng H, Han L, Qiang Z, Zhang X, Gao W, Zhao K, Song Y. Synergistic combination therapy of lung cancer using paclitaxel- and triptolide-coloaded lipid-polymer hybrid nanoparticles. Drug Des Devel Ther. 2018. 12: 3199-3209.

Liu J, Li F, Ping Y, Wang L, Chen X, Wang D, Cao L, Zhao S, Li B, Kalinski P, Thorne SH, Zhang B, Zhang Y. Local production of the chemokines ccl5 and cxcl10 attracts cd8+t lymphocytes into esophageal squamous cell carcinoma. Oncotarget. 2015. 6: 24978-24989.

Matsumoto R, Tsuda M, Yoshida K, Tanino M, Kimura T, Nishihara H, Abe T, Shinohara N, Nonomura K, Tanaka S. Aldo-keto reductase $1 \mathrm{c} 1$ induced by interleukin-1beta mediates the invasive potential and drug resistance of metastatic bladder cancer cells. Sci Rep. 2016. 6:

Petrich A, Nabhan C. Use of class i histone deacetylase inhibitor romidepsin in combination regimens. Leuk Lymphoma. 2016. 57: $1755-1765$.

Pistritto G, Trisciuoglio D, Ceci C, Garufi A, D'Orazi G. Apoptosis as anticancer mechanism: Function and dysfunction of its modulators and targeted therapeutic strategies. Aging. 2016. 8: 603-619.

Posadas I, Santos P, Cena V. Acetaminophen induces human neuroblastoma cell death through nfkb activation. PLoS One. 2012. 7: 16.

Provencio M, Isla D, Sánchez A, Cantos B. Inoperable stage iii non-small cell lung cancer: Current treatment and role of vinorelbine. Journal of Thoracic Disease. 2011. 3: 197-204.

Qin Y, Camoretti-Mercado B, Blokh L, Long CG, Ko FD, Hamann

KJ. Fas resistance of leukemic eosinophils is due to activation of nf-kappa b by fas ligation. J Immunol. 2002. 169: 35363544.

Rivas-Fuentes S, Salgado-Aguayo A, Pertuz Belloso S, Gorocica Rosete P, Alvarado-Vasquez N, Aquino-Jarquin G. Role of chemokines in non-small cell lung cancer: Angiogenesis and inflammation. J Cancer. 2015. 6: 938-952.

Saputra EC, Huang L, Chen Y, Tucker-Kellogg L. Combination therapy and the evolution of resistance: The theoretical merits of synergism and antagonism in cancer. Cancer Res. 2018. 78: 2419-2431.

Sayour ME, Abd El Salam RM, Elyamany MF, El Sayed AM, El-Awady RA. Combination of paracetamol and the glutathione depleting agent buthionine sulfoximine show differential effect on liver cancer cells and normal hepatocytes. Pharma- cology \&amp; Pharmacy. 2016. Vol.07 No.11: 17.

Slingerland M, Guchelaar HJ, Gelderblom H. Histone deacetylase inhibitors: An overview of the clinical studies in solid tumors. Anticancer Drugs. 2014. 25: 140-149.

Stein JV, Nombela-Arrieta C. Chemokine control of lymphocyte trafficking: A general overview. Immunology. 2005. 116: 1-12.

Stennicke HR, Salvesen GS. Caspases - controlling intracellular signals by protease zymogen activation. Biochim Biophys Acta. 2000. 7: 1-2.

Suraweera A, O'Byrne KJ, Richard DJ. Combination therapy with histone deacetylase inhibitors (hdaci) for the treatment of cancer: Achieving the full therapeutic potential of hdaci. Front Oncol. 2018. 8.

Valdez BC, Brammer JE, Li Y, Murray D, Liu Y, Hosing C, Nieto Y, Champlin RE, Andersson BS. Romidepsin targets multiple survival signaling pathways in malignant t cells. Blood Cancer J. 2015. 16: 83

Vinodhkumar R, Song YS, Devaki T. Romidepsin (depsipeptide) induced cell cycle arrest, apoptosis and histone hyperacetylation in lung carcinoma cells (A549) are associated with increase in p21 and hypophosphorylated retinoblastoma proteins expression. Biomed Pharmacother. 2008. 62: 85-93.

Ward SG, Westwick J. Chemokines: Understanding their role in t-lymphocyte biology. The Biochemical Journal. 1998. 333 (Pt 3): 457-470.

Yu YL, Yiang GT, Chou PL, Tseng HH, Wu TK, Hung YT, Lin PS, Lin SY, Liu HC, Chang WJ, Wei CW. Dual role of acetaminophen in promoting hepatoma cell apoptosis and kidney fibroblast proliferation. Mol Med Rep. 2014. 9: 2077 $-2084$.

Zheng H, Zhao W, Yan C, Watson CC, Massengill M, Xie M, Massengill C, Noyes DR, Martinez GV, Afzal R, Chen Z, Ren X, Antonia SJ, Haura EB, Ruffell B, Beg AA. Hdac inhibitors enhance t-cell chemokine expression and augment response to pd-1 immunotherapy in lung adenocarcinoma. Clin Cancer Res. 2016. 22: 4119-4132.

https://doi.org/10.15616/BSL.2019.25.4.293

Cite this article as: Lee SM, Park JS, Kim KS. Improving Combination Cancer Therapy by Acetaminophen and Romidepsin in Non-small Cell Lung Cancer Cells. Biomedical Science Letters. 2019. 25: 293-301. 